\title{
Uso e Ocupação da Terra no Parque Nacional da Serra da Canastra: uma Análise a Partir da Regularização Fundiária
}

\author{
Land and Use and Occupation in the National Serra da Canastra Park: \\ an Analysis Based on Land Regulation
}

\author{
Gustavo Henrique Cepolini Ferreira ${ }^{1} \bowtie(D)$, Lucas Augusto Pereira da Silva ${ }^{2} \bowtie$ (DD \\ 1Universidade Estadual de Montes Claros, gustavo.cepolini@unimontes.br, \\ https://orcid.org/0000-0003-1010-501X \\ Recebido (Received): 12/03/2018 \\ 2Universidade Estadual de Montes Claros, lucasaugustounimontes@gmail.com \\ Aceito (Accepted): 12/02/2019
}

\begin{abstract}
Resumo: Este trabalho tem por objetivo apresentar um histórico do Parque Nacional da Serra da Canastra (PNSC), consonante com as disputas territoriais e o atual uso e ocupação da terra nessa área, principalmente em função da regularização fundiária dessa Unidade de Conservação desde 2010. A metodologia utilizada baseou-se em análise bibliográfica/documental, nas Geotecnologias (Sensoriamento Remoto e Geoprocessamento) e em trabalhos de campo, para a compreensão da cobertura e do uso da terra no PNSC (área regularizada e não regularizadas). Quanto aos resultados, essa pesquisa mostrou como é contraditório o atual cenário da regularização fundiária do PNSC; na linha espaço-temporal, constatam-se diferentes disputas territoriais em consequência da "contradição fundiária" histórica, que reflete diretamente na vida dos camponeses territorializados nessa área, em tese, não regularizada do Parque; e, em um segundo momento da pesquisa, é possível inferir que os camponeses que estão, sobretudo, na parte Sul do Parque, mantêm o uso da terra ancorado em um modelo de vida singular, respaldo por um manejo que permite os níveis de conservação dos recursos naturais atuais em condições similares ao Parque de 71 mil hectares. Todavia, dentre as contradições detectadas entre o ICMBio e as estratégias jurídicas para consolidação territorial dessa UC, constata-se uma nítida aliança entre conservação-mineração-agronegócio visando expropriar os camponeses para legitimar um Parque, cujas origens históricas já revelam a violência da conservação ambiental sem as pessoas.
\end{abstract}

Palavras-chave: Uso da Terra; Cobertura da Terra; Regularização Fundiária; Campesinato; Unidade de Conservação.

Abstract: The aim of this work is to present an account of the Serra da Canastra National Park (SCNP), aligned with the territorial disputes and the current use and occupation of land in this area, mainly due to the land regularization of this Conservation Unit since 2010. Methodology was based on bibliographical/documentary analysis, on Geotechnologies (Remote Sensing and Geoprocessing) and fieldwork for understanding land cover and land use in the SCNP (regulated and non-regulated area). This research showed how contradictory the current land scenario of Serra da Canastra National Park regulation is. In a spatio-temporal line, different territorial disputes are verified, as consequence of the historical "land contradiction", which reflects directly on peasants' life territorialized in this not regularized area of the Park. In another moment of the research, it is possible to infer that the peasants, who are mainly in the South part of the Park, maintain a land use anchored in a singular model of life, supported by a management that allows the current levels of conservation of the natural resources, in similar conditions to the Park of 71 thousand hectares. However, among the contradictions detected between the ICMBio and the legal strategies for territorial consolidation of this $C U$, there is a clear alliance between conservationmining-agribusiness to expropriate the peasants, aiming to legitimize a Park, whose historical origins already reveal the violence of environmental conservation without people.

Keywords: Land Use; Land Cover; Land Regulation; Peasantry; Conservation Unit. 


\section{Introdução}

Sabe-se que o território é modelado por diversos prismas, bem como fatores econômicos, sociais e ambientais. No entanto, existe forte relação entre estes fatores e o papel do Estado. No decorrer dos anos, a preocupação com a conservação dos recursos naturais vem se intensificando, sobretudo devido aos avanços antrópicos em escala cada vez mais mundializada.

No âmbito das discussões sobre a conservação dos recursos naturais e avanços antrópicos, surgem indagações sobre o discurso conservacionista, sobretudo, ao pensar que esse discurso fomenta a conservação dos recursos naturais sem a presença de seres humanos inseridos nessas áreas. Nessa lógica, ressalta-se que essa visão é um retrocesso no que diz respeito à conservação ambiental (FERREIRA, 2015), e, dessa forma, salienta-se que a presença e ação dos atores no território são responsáveis pela modelagem do mesmo.

Assim, é razoável pensar em cenários diversos de ocupação da terra, tendo-se de um lado o uso da terra por camponeses, que produzem em pequena e média escala, e do outro o território ocupado pelo agronegócio e demais empreendimentos engendrados no sistema capitalista, que tendem a explorar os recursos naturais, exaurindo-os para manter seus níveis produtivos, evidenciando-se contrastes no que tange à conservação ambiental, como evidenciam Bunde e Mendonça (2009), a partir das análises no estado de Goiás, com os impactos da expansão dos agrocombustíveis sobre as famílias camponesas e aos recursos naturais.

Ferreira (2013) apresenta um quadro importante sobre o manejo da terra por parte de famílias camponesas, refletindo na qualidade do solo e na vida dos mesmos. Nessa mesma lógica, Luz (2011) menciona que os camponeses possuem características singulares, ou seja, são zeladores dos recursos naturais, com isso obtêm maior produtividade em suas terras por um longo prazo, conservando também a biodiversidade de suas áreas e circunvizinhança. Diegues (1998 e 2000) também sustenta tais manejos e propõe uma alternativa cunhada na etnoconservação.

Seguindo esse raciocínio, as análises sobre as mudanças (positivas obtendo regeneração ou recuperação de áreas degradadas, ou negativas quando ocorrem processos de degradação dos recursos naturais) ou monitoramento do uso da terra podem estabelecer relação com os aspectos da qualidade de vida dos seres humanos. No entanto, é necessário considerar fatores históricos e socioeconômicos, como é discutido por Espírito Santo et al. (2016 p.10) quando reconhecem que "Indeed, the nexus between environmental degradation and human welfare is controversial, with contrasting results depending on socio-economicand historical factors, environmental setting and public policies."

Destarte, este trabalho tem por objetivo apresentar um paralelo entre o histórico do Parque Nacional da Serra da Canastra (PNSC) e as disputas territoriais, bem como uma análise do uso da terra nessa área, considerando as proposições de Santos e Machado (2015), ao ressaltarem que desde os primórdios de sua criação até o presente período, o PNSC apresenta conflitos relacionados principalmente à regularização fundiária das propriedades inseridas nos limites definidos pelo seu decreto de criação. Assim, a regularização fundiária em UCs remete à transferência de domínio de uma propriedade para o ente público correspondente, nesse caso, leia-se Instituto Chico Mendes de Conservação da Biodiversidade (ICMBio) conforme o Sistema Nacional de Unidade de Conservação da Natureza (SNUC) e outras legislações e normativas respaldadas por levantamentos fundiários, demarcação, vistoria, avaliação e aquisição de terras. Por isso, reitera-se que a regularização fundiária deve reconhecer o direito das famílias camponesas; nesse caso trata-se de um direito de propriedade.

A busca pela compreensão do uso da terra leva-nos a explorar o significado dessa expressão que, para Leite (2011), refere-se à exploração dos recursos naturais presentes na superfície em função de um dado beneficiamento. Assim, a análise do uso da terra realizada por meio computacional deve mantém coerência com os trabalhos de campo. Por isso, nessa etapa buscou-se evidenciar as práticas camponesas, considerando a sua maneira de produção sobre a terra, isso porque uma das justificativas para a expropriação dos camponeses da área não regularizada do Parque está contraditoriamente relacionada à "conservação ambiental".

Como é explicitado por Von Ahn et al. (2014) as avaliações que visam analisar as mudanças nas paisagens/usos/cobertura da terra tendem a ser de extrema eficiência para a gestão territorial, uma vez que é possível subsidiar as tomadas de decisões no que diz respeito ao uso e conservação de recursos naturais e ambientais.

Buscando compreender e discutir, do ponto de vista das concepções geográficas, os fatores históricos e socioeconômicos que abarcam a área de estudo em questão (PNSC), fez-se necessário vincular a essa análise a visão e arcabouço teórico, apresentados nos trabalhos de Ferreira (2013 e 2015), quando este discute as 
disputas territoriais em função da regularização fundiária do Parque, sobretudo, buscando analisar como esta questão afeta a vida dos camponeses e também a daqueles que já não vivem na referida área de estudo.

Para entender as disputas territoriais, foi realizada uma análise bibliográfica sobre tais acontecimentos, bem como trabalhos de campo, a fim de vivenciar esta realidade. Para a análise do uso da terra, foram utilizados os recursos de sensoriamento remoto e do geoprocessamento.

\section{Caracterização da Área de Estudo}

O PNSC está localizado geograficamente na porção Sudoeste do estado de Minas Gerais, inserido no Bioma Cerrado, abrangendo 6 (seis) municípios, a saber: Capitólio, Delfinópolis, Sacramento, São João Batista do Glória, São Roque de Minas e Vargem Bonita (Figura 1). Se considerarmos a Zona de Amortecimento (ZA) com um Parque de aproximadamente 200 mil hectares, somam-se 11 (onze) municípios.

No entendimento de Ferreira (2013), o PNSC teve como momento de sua criação a segunda fase da Ditadura Militar (1971-1985), ressaltando o dito "compromisso ecológico" presente nesse momento da história para amenizar as transformações ocorridas na primeira fase do período militar (1964 - 1970).

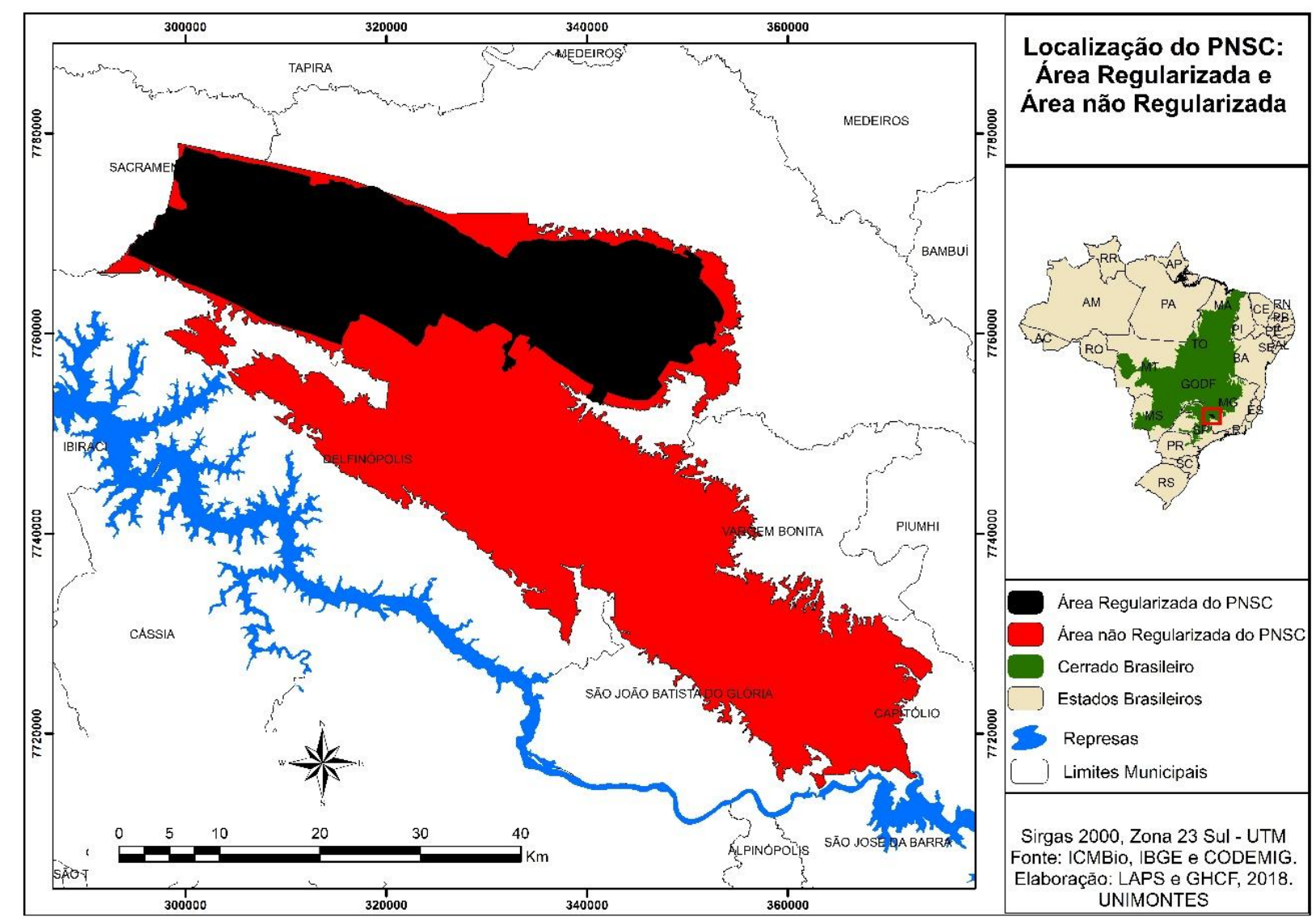

Fonte: ICMBio, IBGE e CODEMIG. Org. Os autores, 2018

Figura 1: Localização do PNSC.

Do ponto de vista hipsométrico, o PNSC está contextualizado entre 686 e 1.503 metros, conforme a Figura 2. A topografia, sem dúvida alguma, é uma das variáveis que mais influenciam as atividades humanas, haja vista que o ser humano, para propagar suas atividades, principalmente no contexto da agricultura em pequena escala, necessita de áreas planas, cujas características são propícias a tais atividades. E neste contexto, as atividades desenvolvidas pelos camponeses no entorno do Parque, são desenvolvidas nas áreas mais planas, sendo enquadradas entre 686 e 1.185 metros de altitude. Reflete também nas atividades pecuárias, sobretudo no rodízio das pastagens, considerando tanto fatores hipsométricos quanto a sazonalidade climática. 


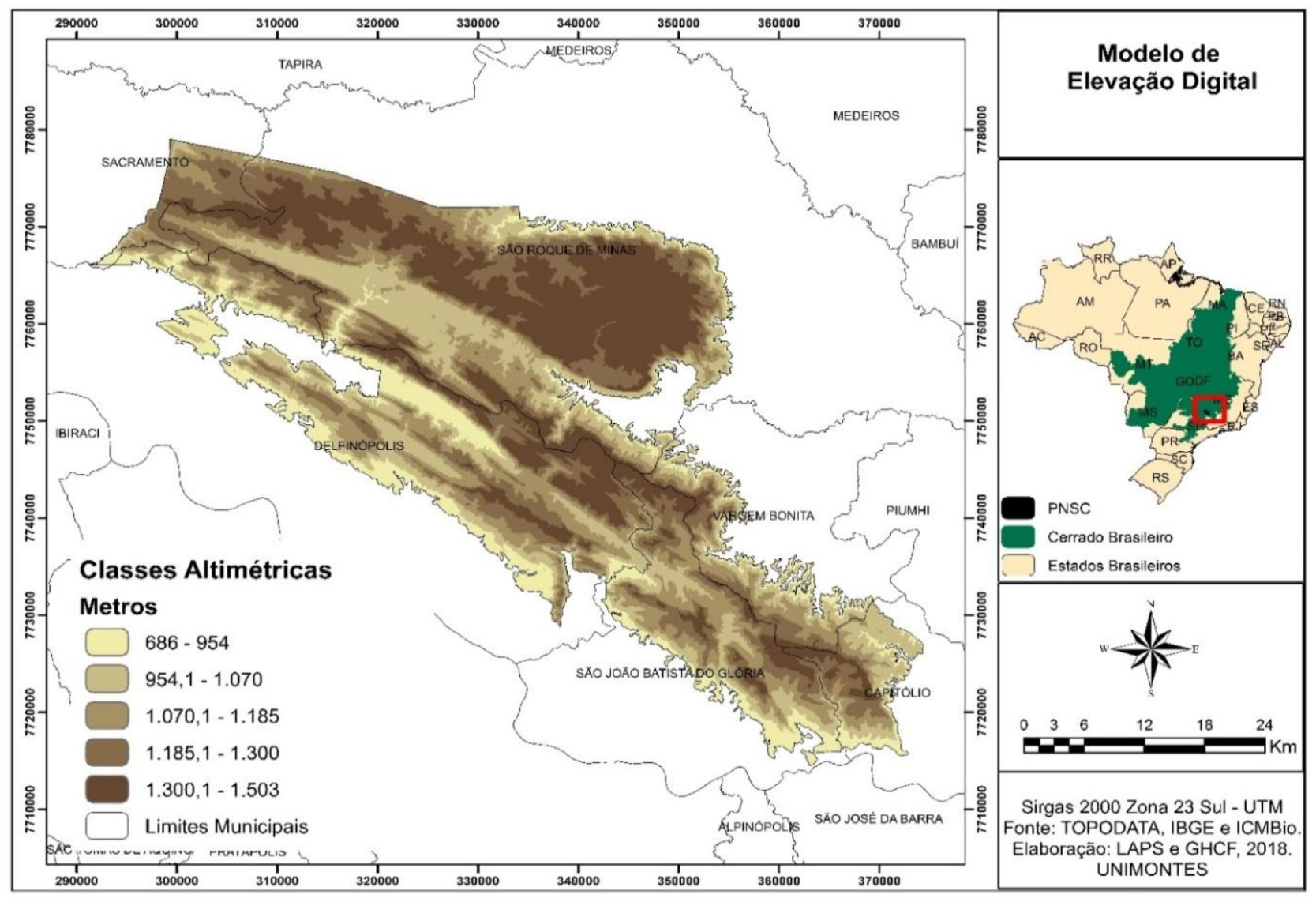

Fonte: TOPODATA, IBGE e ICMBio. Org. Os autores, 2018.

Figura 2: Mapa Hipsométrico do PNSC.

Considerando-se o contexto geológico, de acordo com o mapeamento feito na área de estudo, as unidades geológicas são definidas em: Litofácies micaxisto, Formação Marília, Litofácies anfibolito, Litofácies paragnaisse e xisto feldspático, Formação Paracatu indivisa, Sequência Turbidítica, Membro Hidroelétrica da Batalha, Formação Chapada dos Pilões, Formação Serra da Saudade, Formação Cubatão (Figura 3).

Baseando-se no contexto geoecológico, Santos (2014) indica que o PNSC apresenta savanas e formações campestres nos interflúvios e formações florestais nos fundos de vales. Ainda para esta autora ( $o p$ cit), a região está inserida no seguinte contexto climático: regime climático tropical ocorrendo uma estação seca e outra chuvosa, e dentro das concepções do modo de vida dos camponeses, esse regime climático é essencial para suas atividades, como também é demonstrado nos estudos de Ferreira (2013) sobre o manejo das pastagens e, sobretudo, refletem diretamente na produção artesanal do queijo Canastra, conforme pesquisas de Barbosa (2007) e Simoncini (2017).

No que concerne à administração do PNSC, desde 2007 o órgão responsável é o ICMBio, e, de acordo com a página oficial do ICMBio na internet, este órgão administra 324 unidades de conservação federais, totalizando cerca de 79,2 milhões de hectares. Dentro dos 79,2 milhões de hectares, aproximadamente 10,5 milhões de hectares constituem as 57 UCs federais que podem permanecer sob domínio privado, ou seja, Área de Proteção Ambiental, Área de Relevante Interesse Ambiental, Refúgio de Vida Silvestre e Monumento Natural (ICMBio, 2017). 


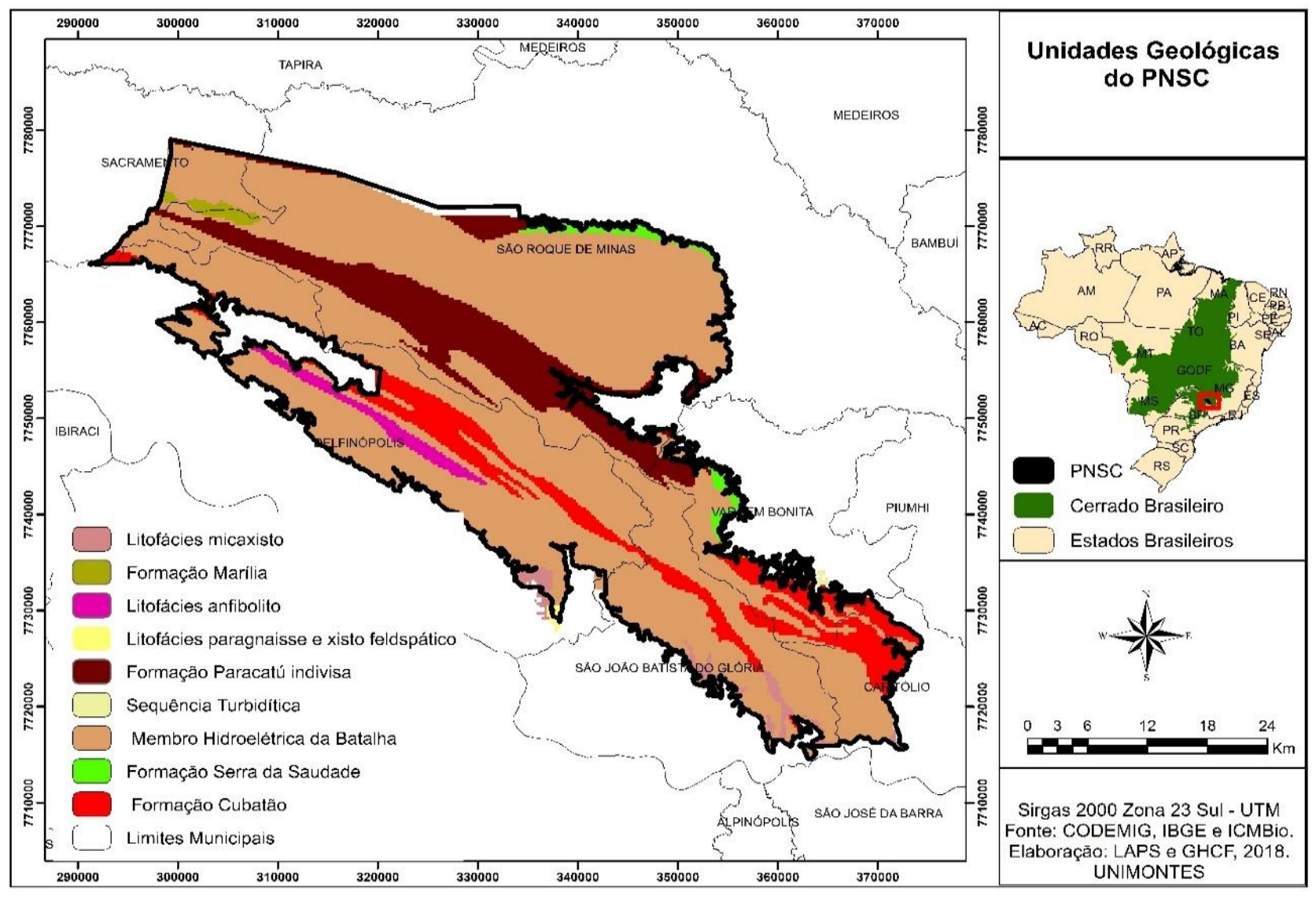

Fonte: CODEMIG, IBGE e ICMBio. Org. Os autores, 2018.

Figura 3: Mapa Geológico do PNSC.

\section{Procedimentos Metodológicos}

Para execução deste trabalho, os procedimentos metodológicos tiveram carácter técnico por meio das Geotecnologias, sobretudo, com as técnicas de Sensoriamento Remoto e Geoprocessamento, sendo ferramentas basilares para o entendimento e monitoramento da dinâmica do uso e ocupação da terra.

Seguindo este raciocínio, deu-se início aos procedimentos metodológicos, a partir de visita a campo com o intuito de embasar o mapeamento do uso e ocupação da terra nas áreas do Parque Nacional da Serra da Canastra. O trabalho de campo é um momento ímpar para as análises que envolvem o manejo da terra, sobretudo quando se pondera que uma imagem de satélite, mesmo sendo de alta resolução espacial, por si só não expressa de maneira qualitativa e humana os acontecimentos materializados na realidade.

Em um segundo momento metodológico, foi montado um banco de dados sobre as bases cartográficas utilizadas neste estudo, a saber: bases de Geologia, Topografia, Limites Municipais, Estaduais e do Parque Nacional da Serra da Canastra e principalmente os produtos orbitais, sendo estes obtidos no site do Instituto Nacional de Pesquisas Espaciais (INPE). Com relação aos produtos orbitais, foram obtidos do satélite Landsat - 8 OLI (Operational Land Imager), referentes às órbitas 219 e 220 e ponto 074.

Uma vez que o PNSC possui uma área relativamente extensa, foram necessárias duas cenas de satélite para compor a área de estudo. Salienta-se que foram escolhidas imagens de datas diferentes, no entanto a diferença foi relativamente pequena, sendo a imagem da órbita 220 do dia 14 de outubro de 2017 (com inclinação solar de $61.92^{\circ}$ ) e a imagem da órbita 219 do dia 05 do mesmo mês e ano (inclinação de $59.70^{\circ}$ ).

O processamento digital das imagens foi realizado no software Erdas 2014. Inicialmente foi feita a composição colorida RGB (Red, Green e Blue) das imagens, sendo que foram utilizados os seguintes canais (bandas): 6 (Infravermelho médio) 5 (Infravermelho Próximo) 4 (Vermelho visível), nessa mesma sequência, pois a mesma origina a composição colorida com "falsa cor" para a cena, essa composição foi feita através da ferramenta Layer Stack.. Após a composição, foi feito um mosaico das cenas através da ferramenta MosaicPro from $2 D$ View. As características dos canais utilizados encontram-se descritas na Tabela 1. 
Tabela 1: Características das Bandas utilizadas.

\begin{tabular}{cccc}
\hline Bandas & Características & $\begin{array}{c}\text { Comprimento de onda } \\
\text { (micrometros) }\end{array}$ & $\begin{array}{c}\text { Resolução espacial } \\
\text { (metros) }\end{array}$ \\
\hline 4 & Visível Vermelho & $0.64-0.67$ & 30 \\
5 & Infravermelho Próximo & $0.85-0.88$ & 30 \\
6 & Infravermelho & $1.57-1.65$ & 30 \\
& Médio/SWIR & & \\
\hline \multicolumn{4}{c}{ Fonte: Serviço Geológico dos EUA. Org. Os autores, 2018. }
\end{tabular}

Após a leitura e interpretação das cenas, foi feita a classificação do uso e ocupação da terra para as áreas do PNSC, no entanto, para atingir o objetivo deste trabalho, foi realizado o cálculo da área regularizada e não regularizada do PNSC, e, na sequência realizou-se o mapeamento.

Com os dados sobre o uso e ocupação da terra, foram gerados mapas temáticos no software Arcmap, em seguida gerou-se os gráficos dos percentuais do uso da terra no software Excel 2013. Após a organização dos dados, foi necessário compilar o embasamento teórico e científico sobre os conceitos de uso e cobertura da terra, a partir do contexto em que se encontra o PNSC, sobretudo aplicar os dados, conceitos e as concepções geográficas que os abarcam.

\section{Resultados e Discussões}

Antes de iniciar as discussões relativas à compreensão da distribuição espacial dos usos e ocupações da terra no PNSC, é de extrema importância entender o cenário contraditório em que se encontra esta área, sobretudo a partir da suposta irregularidade fundiária, apregoada pelo ICMBio, que atualmente vem sendo questionada judicialmente, inclusive pelos camponeses, como já abordado nas pesquisas de Oliveira (1992), Goulart e Risso (2010), Fernandes (2012) e Ferreira (2011, 2013 e 2015).

Tomando-se por base esta ótica, ressalta-se que nos 130 mil hectares do PNSC estão inseridas famílias de camponeses que se organizam de maneira singular, sobretudo nos aspectos culturais, e mantém historicamente uma relação harmoniosa com a terra de trabalho e vida, realizando a manutenção de seu uso sem que haja devastações que comprometam o potencial ambiental de suas propriedades.

No entanto, essa relação harmoniosa com a terra vem sendo perturbada pela lógica capitalista, aliada às ações do Estado que é conivente com o agronegócio, mineração e seus empreendimentos, bem como com contraditórias políticas ambientais compensatórias; as quais fomentam uma disputa territorial e colocam os camponeses em constantes conflitos sob a égide da conservação. Assim, violam-se o direito de propriedade, bem como os direitos humanos desde a criação do Parque em 1972.

Com isso, Ferreira (2015) mostra algumas propostas que foram apresentadas para a regularização do PNSC, argumentando que a partir do Plano de Manejo do ano de 2005, e do Grupo de Trabalho Interministerial (GTI) do ano de 2006, cujos documentos ratificaram a existência do Parque Nacional com aproximadamente 200 mil hectares, dentro da linha temporal, houve mobilizações principalmente por parte dos camponeses em busca da permanência na área de 130 mil hectares. Atualmente perícias, acordos, processos e projetos de lei seguem judicializados.

Ainda de acordo com as análises de Ferreira (2015), deve-se compreender que essa lógica contraditória de articulações e estratégias de regularização fundiária do PNSC é um retrocesso no que diz respeito às discussões sobre conservação ambiental no Brasil, haja vista que o argumento do ICMBio insiste, em parte, na conservação sem as pessoas.

Nessa perspectiva, foram feitas visitas na página oficial do ICMBio, dentre essas visitas foi observada a seguinte nota: "Conquistas na Regularização Fundiária", datada de 31 de agosto de 2017, evidenciando que o ICMBio obteve a legalização de 14 milhões de hectares de terra desde o período de sua criação (10 anos). Trata-se de uma nítida, e por vezes perversa, aliança com o agronegócio, mineradoras e demais empreendimentos que impactam o ambiente.

De certa forma, fica explícito que há uma acentuada ação do Estado em prol da regularização fundiária do PNSC, sobretudo do órgão ICMBio, tomando-se como exemplo referência o Edital ICMBio n ${ }^{\circ}$ 01/2010, que estabelece os procedimentos legais para "Desoneração de Reserva Legal", tendo como alvo os proprietários de imóveis no interior do PNSC, a partir do entendimento de que essa Unidade de Conservação é de 200 mil hectares.

Em linhas gerais, essa proposta baseia-se na vertente de que as áreas do PNSC, de domínio privado (que devem ser de domínio público), poderiam ser compradas e posteriormente doadas ao ICMBio, para atingir 
uma UC de aproximadamente 200 mil hectares. Em compensação por essa ação, os proprietários rurais que participassem deste processo, ficariam liberados da obrigação de manter e/ou recuperar sua reserva legal do imóvel fora da Unidade de Conservação.

Sabe-se que há no Brasil várias contradições socioeconômicas, e é fato que um dos grandes motivos para estas contradições, deve-se ao perverso modelo capitalista imposto sobre o território, e, diante dessa argumentação, e do cenário apregoado pelo Edital analisado e debatido, pode-se acrescer que haverá mais uma situação contraditória, uma vez que, o agronegócio (e outros empreendimentos) por possuir grande fonte de capital, será ainda mais beneficiado, comprando as terras, em tese não regularizadas do PNSC, e doandoas ao ICMBio. Este fato aumenta as tensões e conflitos territoriais no PNSC, afetando de maneira direta a vida dos camponeses dentro da referida área. Soma-se a este cenário, o fato das dificuldades do próprio ICMBio em gerir essas áreas descontínuas, que atualmente limitam-se com muitas propriedades camponesas.

Outro fato contraditório que está presente no referido edital, é a seguinte situação: de acordo com as regras do Edital de 2010, os municípios das bacias hidrográficas (a priori no estado de Minas Gerais) do rio São Francisco, do rio Grande e do rio Paranaíba, que possuam propriedades em desobediência com a Reserva Legal, poderão comprar porções de terras não regularizadas do PNSC e doá-las ao ICMBio, como forma de compensar a Reserva Legal nas suas propriedades, localizadas geograficamente nessas 3 bacias hidrográficas, conforme mapeado na Figura 4.

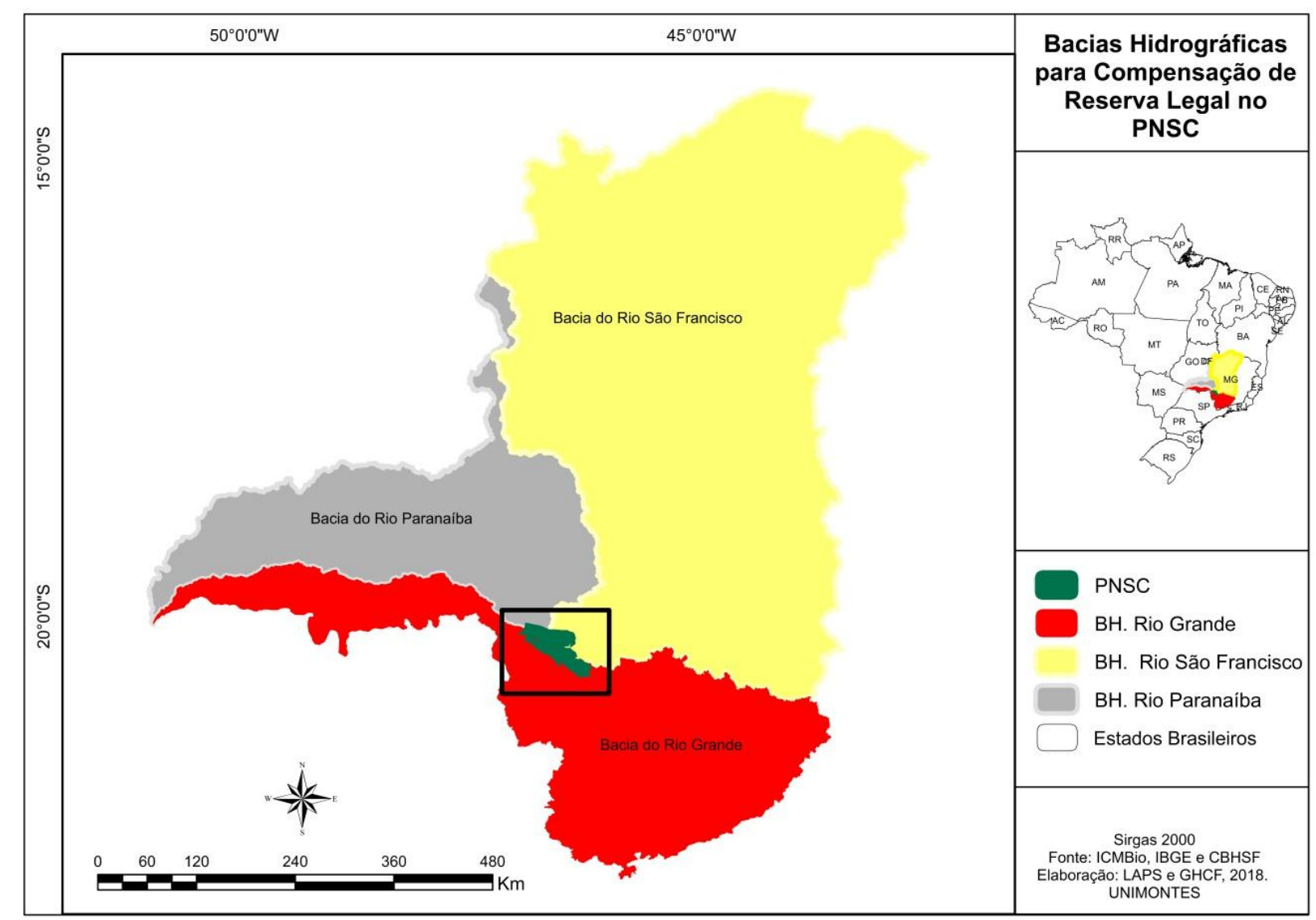

Fonte: ICMBio, IBGE e CBHSF. Org. Os autores, 2018.

Figura 4: Localização de Bacias Hidrográficas para Compensação de Reserva Legal no PNSC.

Vale ressaltar que esse processo de compensação de Reserva Legal, pode ocorrer em outras UCs no território brasileiro. Essa afirmativa baseia-se na discussão de Ferreira (2013), e em uma análise da página do ICMBio na internet, onde verificou-se um Edital com o mesmo objetivo, ou seja, a "regularização fundiária da Reserva Biológica de Perobas", localizada no estado do Paraná. Observou-se também que no Parque Nacional das Araucárias (localizado em Santa Catarina) há tramitação de processos advindos de compensação, bem como no Parque Nacional do Catimbau em Pernambuco. Essa realidade é observada também nos Parques Nacionais da Chapada da Diamantina (na Bahia), Serra da Bodoquena (no Mato Grosso do Sul) e Ilha Grande (entre o Paraná e Mato Grosso do Sul), nos quais constatou-se processos em andamento para o mecanismo de compensação social e ambiental da reserva legal. Isso revela a grande irregularidade fundiária nas UCs brasileiras. 
Analisando ainda os meios de comunicação do ICMBio, Lima (2011) verificou que o PNSC recebeu, no ano de 2010, uma área de 450 hectares como doação para compensação social de reserva legal. Trata-se do primeiro passo para a regularização de outras propriedades por meio dessa ação (mecanismo de doação), que prevê a desoneração da obrigação de recomposição de reserva legal mediante doação de terra ao órgão ambiental que possui a responsabilidade das UCs, como já foi argumentado neste estudo. Dito isto, salientase que o agronegócio está atrelado ao Estado para execução da regularização fundiária.

Dentro dessa lógica, o ICMBio almeja atingir os 200 mil hectares, "regularizando" as terras do PNSC através dos mecanismos analisados, cujos impactos seguem obscuros. Salienta-se que é uma lógica na qual os interesses antagônicos saltam de imediato, ou seja, os empreendimentos com determinados impactos, tais como a mineração, usinas hidrelétricas, turismo e, como já mencionado, o agronegócio. Assim, reforça-se a afirmação de que o referido órgão está preocupado somente em atender às perspectivas e necessidades do Parque, sem a devida atenção ao verídico papel social e territorial histórico dos camponeses nessa área, os Canastreiros.

Em uma análise dos dados quantitativos e das bases cartográficas do ICMBio das áreas do PNSC, doadas ao referido órgão, atentou-se em fazer uma análise da evolução temporal das referidas doações, contemplando as doações de 2010 até 2016 e conseguinte a 2017. Na Figura 5 apresenta-se o mapa temático com tais informações.

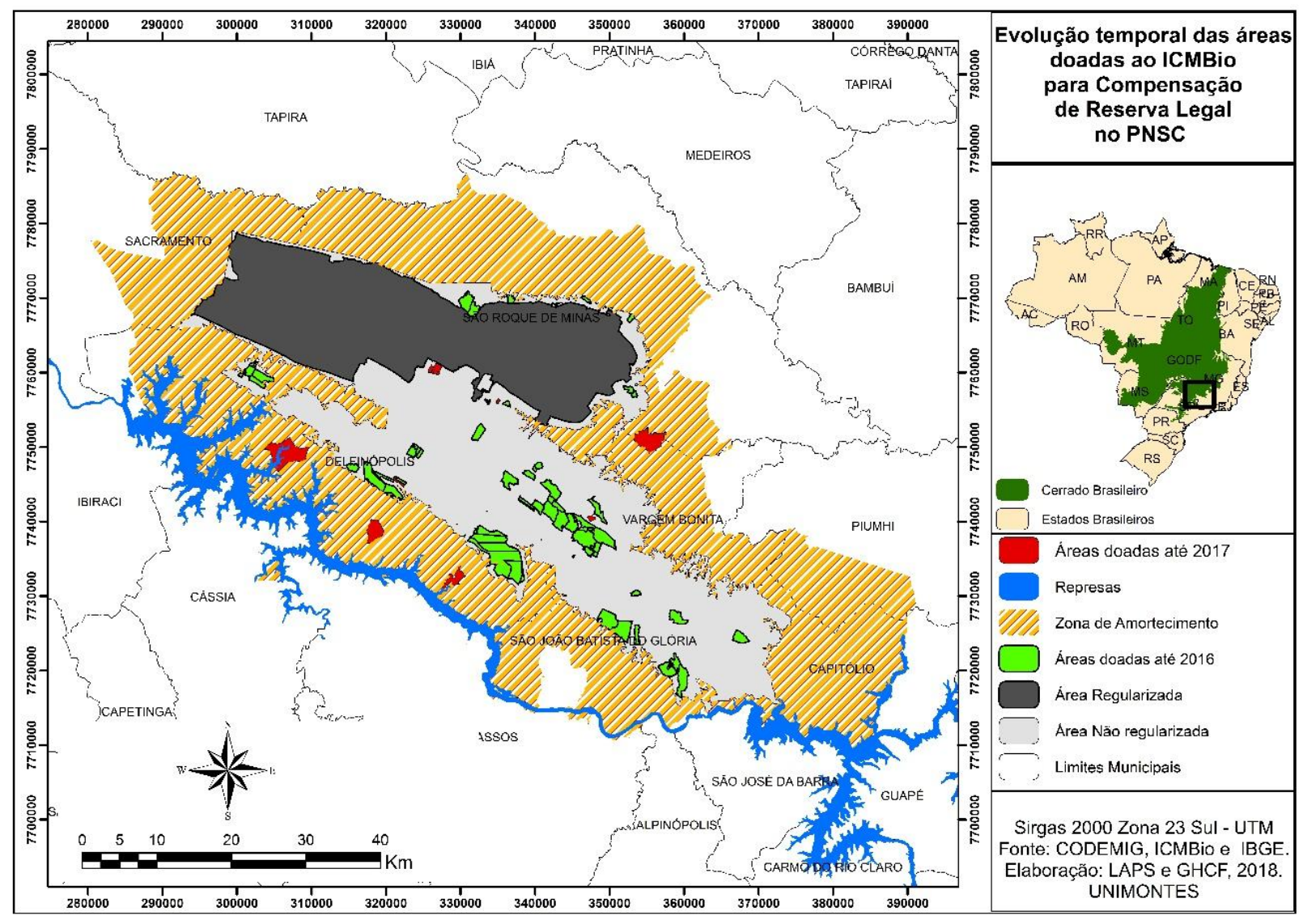

Fonte: CODEMIG, ICMBio e IBGE. Org. Os autores, 2018.

Figura 5: Evolução temporal das áreas doadas ao ICMBio para Compensação de Reserva Legal no PNSC.

Com relação às áreas doadas até 2017 (em vermelho), ressalta-se que as áreas registradas na Zona do Amortecimento do PNSC são áreas urbanas, em tese, excluídas dos decretos e propostas de regularização fundiária, conforme relato dos analistas ambientais do PNSC em fevereiro de 2018. Para dar prosseguimento às análises, o Quadro 1 sistematiza as áreas doadas ao ICMBio entre 2012 e 2017 que já ultrapassa os 20 mil hectares. E, somando-se aos 71.525, em tese regularizados desde 1972, o PNSC atinge hoje 92.160 hectares regularizados. Trata-se de uma estratégia contraditória no que tange as demarcações jurídicas e territoriais, e, sobretudo, no cotidiano dos camponeses confrontantes com as áreas doadas ao ICMBio, que por sua vez não possui qualquer ação nas mesmas para legitimar os processos, ou seja, a posse efetiva dessas áreas descontínuas; evidencia-se, portanto, que tal prática em tese desonera o ICMBio de adquirir às terras com recursos da União. Todavia, recria novos e permanentes conflitos territoriais e jurídicos enfraquecendo os argumentos técnicos e financeiros deste procedimento de regularização e reordenação fundiária. 
Quadro 1: Evolução das doações ao ICMBio entre 2012 e 2017.

\begin{tabular}{cc}
\hline Ano das doações & Área em Hectares \\
\hline Até março de 2012 & 3.828 \\
Até fevereiro de 2013 & 9.600 \\
Até 2016 & $17.305,72$ \\
Até 2017 & $20.635,49$ \\
\hline \multicolumn{2}{c}{ Fonte: ICMBio. Org. Os autores, 2018. }
\end{tabular}

Ao mostrar a evolução das áreas doadas ao ICMBio, do ponto de vista quantitativo, observa-se um acréscimo significativo nas áreas doadas, sendo um aumento de 3.329,77 hectares, isso em um intervalo tempo muito pequeno (menos de 1 ano) ao analisarmos o período de 2016 e 2017. Salienta-se que o número de áreas doadas foi maior também, em 2016; foram 91 áreas doadas, já em 2017 esse número passa de 103 áreas. De acordo com as bases cartográficas do ICMBio, já são contabilizados mais de 92 mil hectares sob domínio do ICMBio. No entanto, é de extrema importância apontar algumas indagações quanto às doações do ano de 2017. Uma dessas indagações é norteada por uma análise do mapa da Figura 5, observa-se que quatro propriedades doadas ao ICMBio, inseridas na ZA, sendo que, pelo aspecto legal isso não possui respaldo, uma vez que segundo o Decreto $n^{\circ} 70.355 / 1972$, são proibidas doações de áreas que estejam fora da extensão do PNSC. Diante dessa problemática, surgem as seguintes indagações: com qual respaldo e mecanismo o ICMBio recebeu essas áreas doadas, mesmo estando fora do PNSC? Seria essa mais uma estratégia contraditória da já indicada aliança conservação-mineração-agronegócio, aliando forças para se sobrepujarem ao sistema judiciário?

É importante salientar que, segundo informações obtidas através de entrevistas com os analistas do ICMBio, as áreas que discutimos no cunho ilegal perante o decreto, são áreas urbanas excluídas, e não doações. Todavia, surge outra indagação: por que essas áreas estão inseridas nas bases cartográficas oficiais do ICMBio? Ainda sobre os dados, foi possível verificar os mesmos através de uma solicitação no Sistema Eletrônico do Serviço de Informação ao Cidadão conforme protocolos de fevereiro e março de 2018, nos quais constatou-se que: "Até a presente data foram doados ao ICMBio, por compensação de reserva legal no Parque Nacional da Serra da Canastra, cerca de 12 mil hectares. Outros 2700 hectares foram habilitados para tal finalidade, mas ainda não foram doados”. Diante dessas informações, reitera-se que há um desencontro nas informações dentro do próprio órgão ambiental, que permite reafirmar que a irregularidade não é apenas fundiária.

Após essa análise do cenário fundiário do PNSC, em consonância com a lógica imposta sobre a conservação ambiental sem pessoas, é muito importante reforçar que dentro dos 130 mil hectares (área não regularizada) há exploração mineral, sobretudo, de quartzito e o grande interesse das mineradoras, de kimberlitos (diamantes), ao Sul do Parque e além de outras áreas, com elevados valores no mercado internacional, conforme evidenciado na Figura 6. Tais hipóteses devem ser levadas ao patamar jurídico, para redefinição e até mesmo anulação dessas doações, pois as compensações descompensadas como cunhou Ferreira (2013), reforçam que para muitos camponeses, o Parque é o confrontante ilegal, o mesmo de outrora, sob a égide do autoritarismo.

Para discutir sobre uso da terra e cobertura da terra, é importante distinguir tecnicamente esses termos. De acordo com FAO (1995), o uso da terra está relacionado ao critério funcional, e assim pode-se argumentar que está direcionado ao uso da terra como ela é utilizada pelas populações. Já a cobertura da terra está relacionada ao estado biofísico da superfície, sendo esta superfície coberta por um determinado objeto em um dado momento. A cobertura pode ser formação vegetal, podendo ser nativa ou antropogênica, uma construção que cobre a superfície, como por exemplo, um empreendimento de um armazém, as rochas e demais características da Terra. É importante saber que o uso da terra e a cobertura da terra estão intimamente correlacionados, haja vista que as atividades humanas exercidas sobre a superfície geralmente estão relacionadas a um tipo específico de cobertura superficial que reveste o solo (IBGE, 2006). 


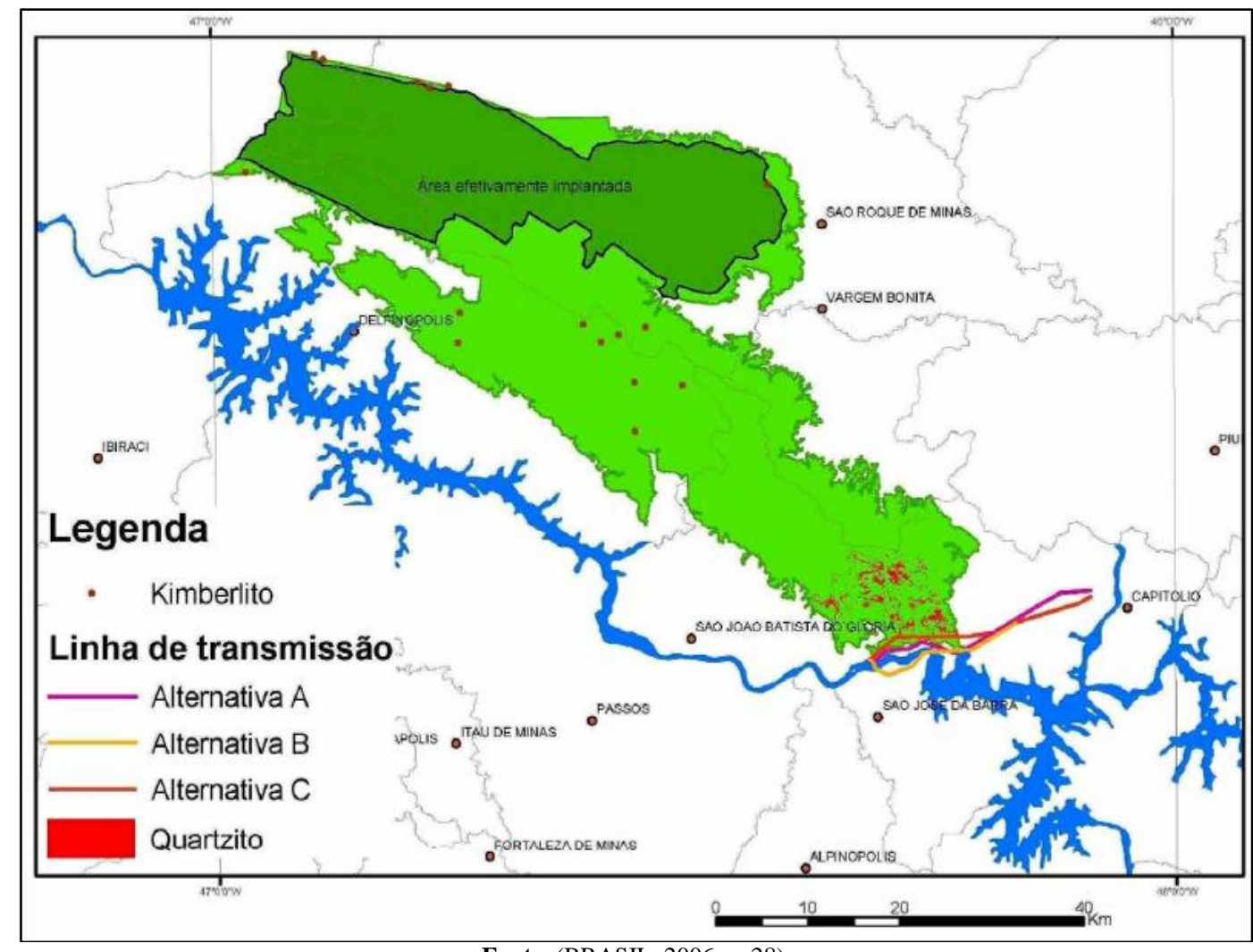

Fonte: (BRASIL, 2006, p. 28).

Figura 6: Evidência da exploração mineral no PNSC.

Na Figura 7 apresenta-se o mapa de cobertura vegetal gerado a partir das imagens OLI para a área regularizada do PNSC:

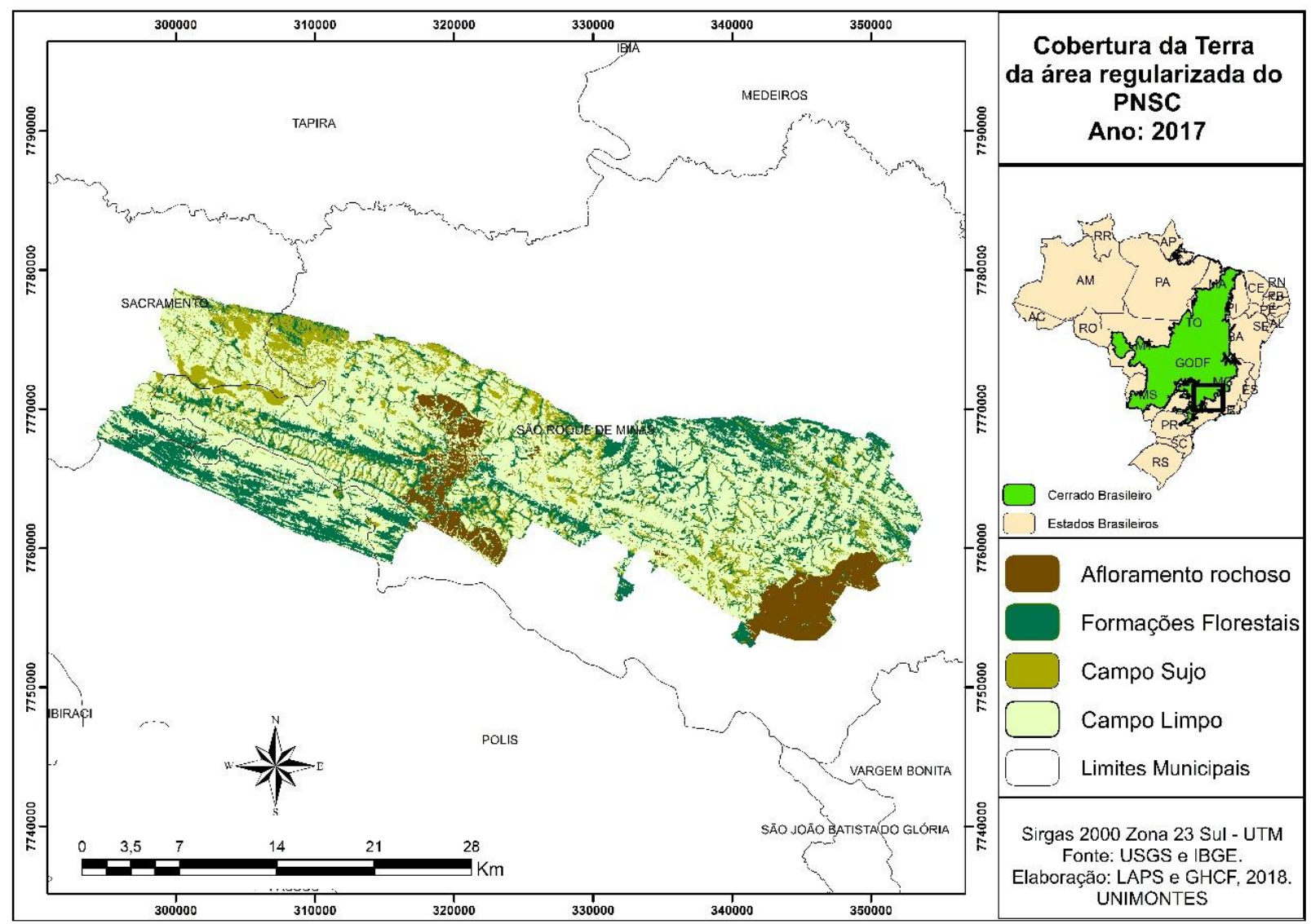

Fonte: USGS e IBGE. Org. Os autores, 2018.

Figura 7: Cobertura Vegetal da Ârea Regularizada do PNSC. 
Na Figura 8, estão sistematizados os dados com os percentuais da cobertura da terra a partir deste mapeamento:

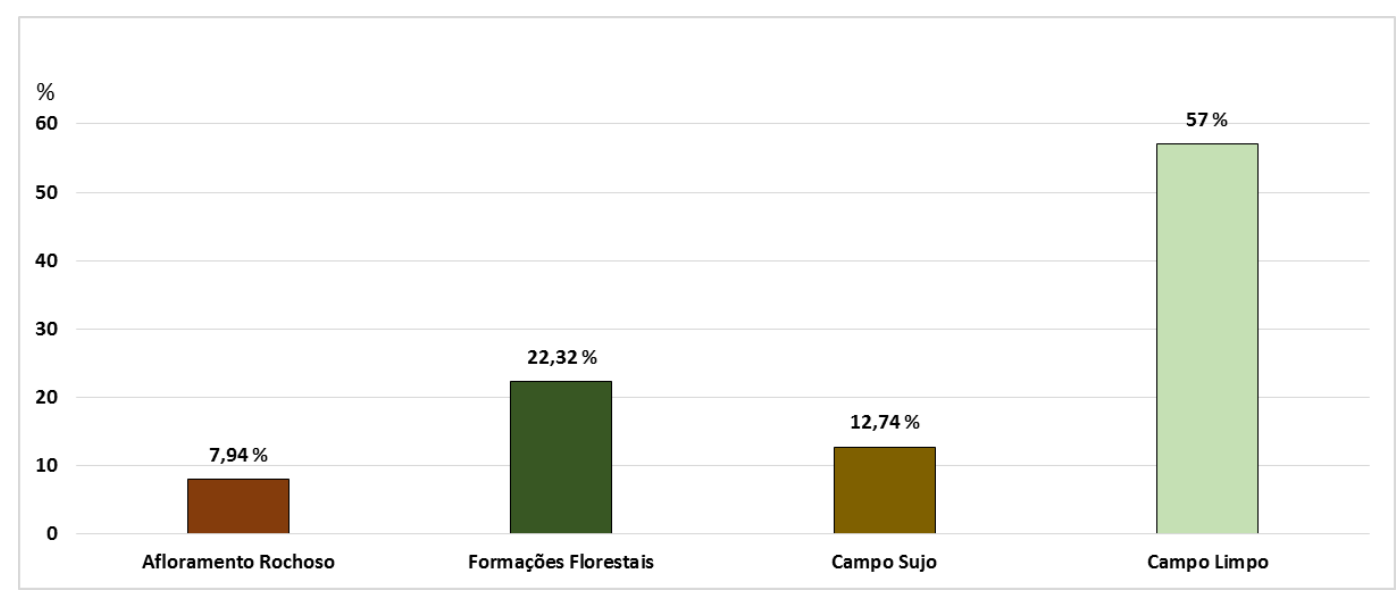

Fonte: Análise computacional. Org. Os autores, 2018.

Figura 8: Área em Percentual (\%) da cobertura da terra na área regularizada do PNSC.

No mapeamento para esta área, foram estimados $7,94 \%$ da distribuição territorial para áreas de afloramento rochoso, sendo áreas com rochas expostas no PNSC, considerando que são áreas cuja topografia é relativamente elevada, variando de classes altimétricas de 1.300 a $1.503 \mathrm{~m}$ (Figura 2). As áreas de afloramento rochoso no PNSC possuem, em determinados pontos, a presença de formações campestres, sobretudo nos topos montanhosos "chapadões".

As áreas de formações campestres ocupam no total 69,74\% da área regularizada do PNSC; são subdivididas em duas classes, o campo limpo e campo sujo. O campo limpo possui as seguintes características evidenciadas em campo: fitofisionomia herbácea com poucos arbustos, uma vegetação rasteira e espaçada no solo, possuindo 57\% da distribuição do PNSC. Já as áreas de campo sujo: apresentam uma fitofisionomia com presença de arbustos e subarbustos, espaçados na superfície e possuindo $12,74 \%$ em extensão territorial na área regularizada do PNSC.

As áreas de formações florestais que recobrem 22,32\% da área regularizada do PNSC, e são compostas por: vegetação arbórea, arbustiva, floresta estacional semidecidual, savana, matas de galeria e vegetação secundária.

Nos dados apresentados no mapeamento, é notório o nível de conservação do PNSC, mesmo com os episódios de queimadas registrados nos últimos anos, portanto, essa representação cartográfica será comparada com a área não regularizada, principalmente para demonstrar que os camponeses inseridos no entorno do PNSC mantêm uma relação de harmonia e conservação com o uso da terra - natureza. 
Na Figura 9 apresenta-se o mapa de uso da terra na extensão da área não regularizada do PNSC:

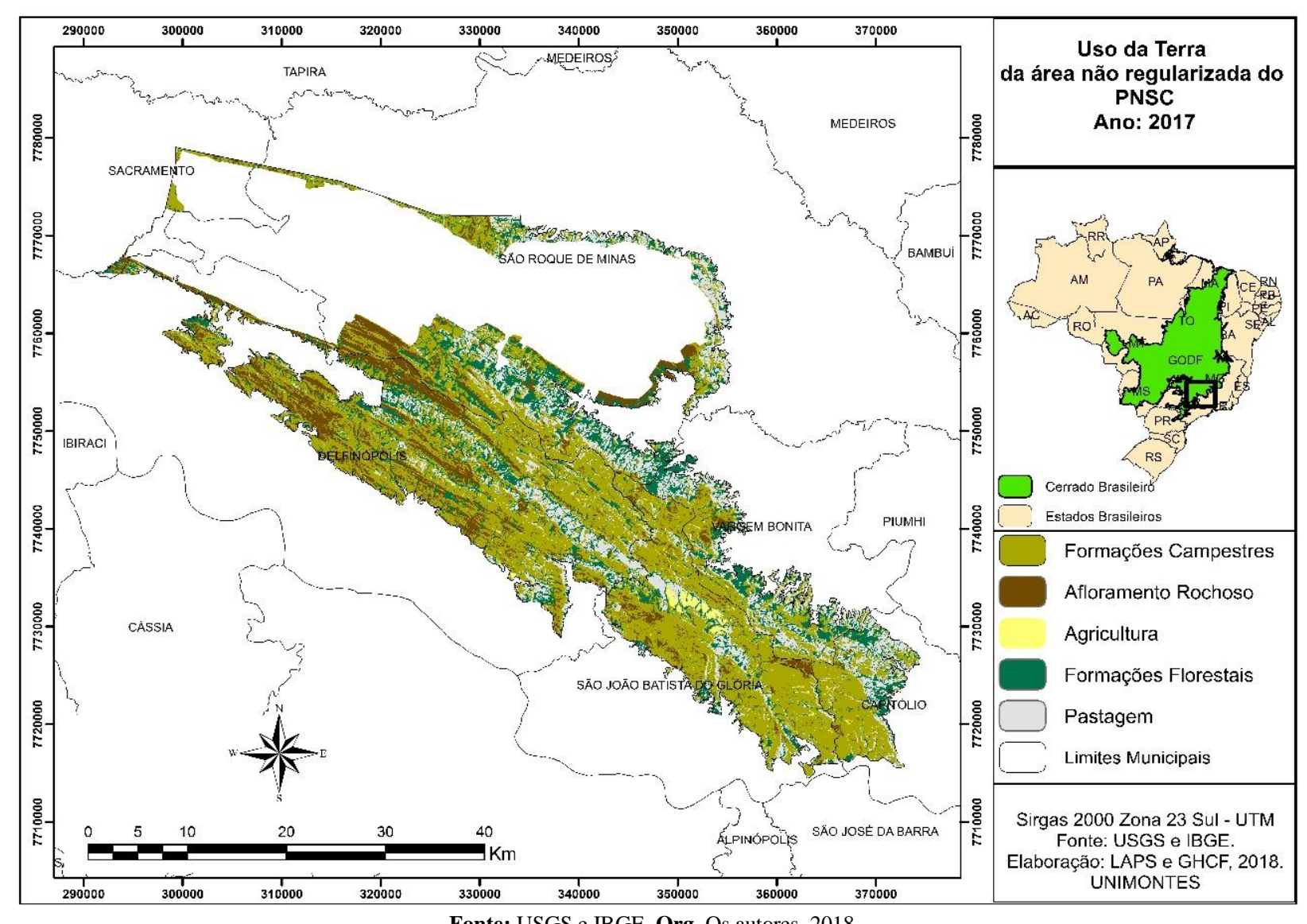

Figura 9: Uso da terra da Área Não Regularizada do PNSC.

A Figura 10 apresenta os percentuais das classes de uso da terra para a área não regularizada do PNSC:

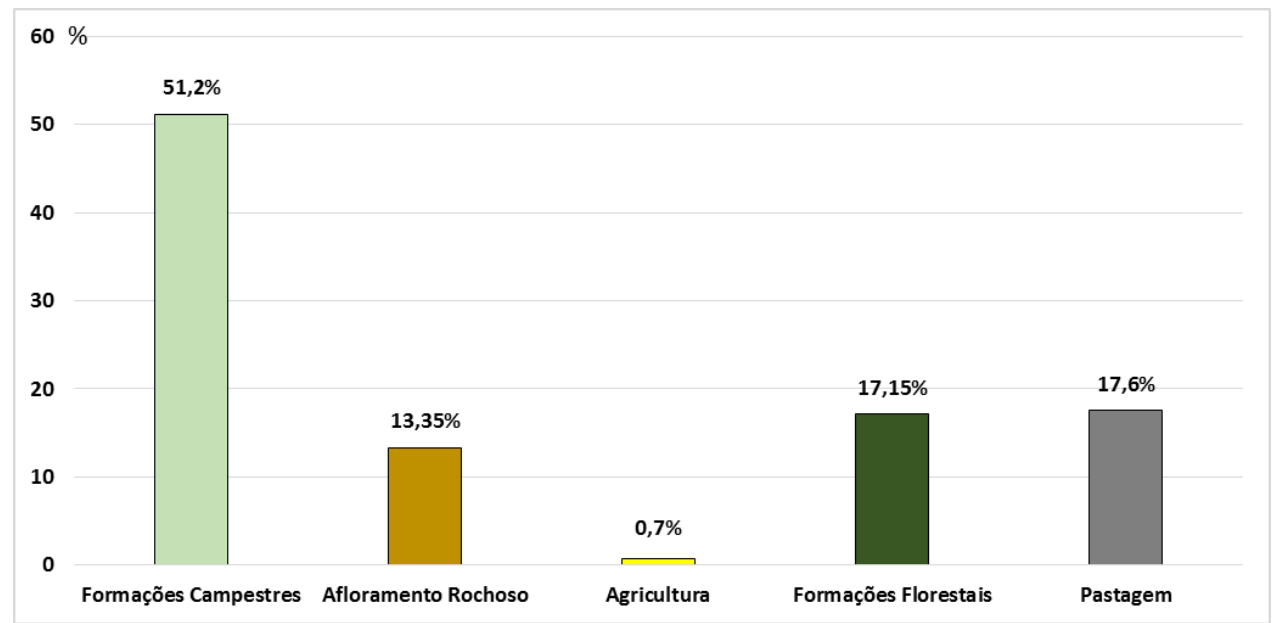

Fonte: Análise computacional. Org. Os autores, 2018.

Figura 10: Área em Percentual (\%) do uso da terra na área não regularizada do PNSC.

É possível observar a grande espacialização de formações campestres em todos os paralelos geográficos da extensão não regularizada do PNSC. Vale ressaltar que, devido a extensão desse recorte espacial, não foi possível discriminar campo limpo de campo sujo, no entanto dentro da classe vegetacional "formações campestres" as classes supracitadas foram inseridas. É importante mencionar que entre os motivos da generalização dessas classes é devido a confusão na interpretação, e optou-se por esse meio para evitar erros na classificação. Essa classe representa $51,2 \%$ da distribuição espacial da extensão territorial analisada (área 
não regularizada). Em conjunto com as formações florestais, a vegetação nativa da área não regularizada totaliza $69,35 \%$ da extensão territorial, mostrando assim um alto grau de conservação, quando comparada com as "áreas intactas" do PNSC já regularizadas com o decreto de 1972.

A vegetação nativa é de extrema importância para a dinâmica ambiental, tendo em vista o potencial ecológico que as mesmas possuem, manutenção da fauna, regulador térmico, proteção para os recursos hídricos (matas ripárias), proteção do solo, já que do ponto de vista hidro - geomorfológico, a vegetação protege as camadas superficiais do solo de eventos erosivos, lixiviação e demais danos ambientais, sobretudo, sendo grande responsável pela manutenção das águas subterrâneas.

A classe de afloramento rochoso representa $13,35 \%$ da extensão das áreas não regularizadas; salienta-se que ao Sul dessa extensão, há predomínio de áreas destinadas à exploração mineral (vide Figura 6).

Para a classe de agricultura, chama-se a atenção para esta estimativa do percentual, aproximadamente $0,7 \%$ do território não regularizado do PNSC são destinados sobremaneira à agricultura camponesa. Salientase que o uso da agricultura, bem como as pastagens revelam o modo de vida dos camponeses, ou seja, há um nítido uso dessa agricultura consorciada às pastagens, totalizando assim o montante de aproximadamente $18,3 \%$ por essa população territorializada no entorno do PNSC.

Ainda sobre as áreas de pastagem, deve-se ressaltar para além dos números, no caso o percentual de $17,6 \%$, pois, os aspectos qualitativos norteiam as ações tomadas pelos camponeses, sobretudo, no manejo das pastagens, seja nas baixadas e chapadões, muitas vezes manejando inclusive o fogo, como uma característica fundamental para utilização dos capins nativos.

Barbosa (2007) e Ferreira (2013) apresentam de maneira ímpar a forma como os camponeses manejam essas pastagens, manejo este realizado com subsídio histórico do fogo, principalmente visando não afetar os recursos naturais; os autores descrevem que os camponeses "montam" uma barreira natural - aceiros para que o fogo não afete as nascentes e demais áreas de vegetação nativa.

Esses fatos evidenciam a forma zelosa com que os camponeses lidam com a terra, cabe salientar que os mesmos, possuem uma preocupação com o futuro e consequentemente com as gerações vindouras. No entanto, há grandes chances da desapropriação ocorrer em um curto espaço de tempo, tendo em vista que as articulações do ICMBio, por meio dos mecanismos contraditórios, vêm conseguindo regularizar as demais áreas do PNSC, sob o argumento de que o Parque deve ter 200 mil hectares. Enquanto isso, as demandas judiciais seguem sob a morosidade habitual, e aos camponeses cabe a resistência na terra de trabalho e vida.

\section{Considerações Finais}

Esta pesquisa mostrou o quanto o cenário no qual se encontra a regularização fundiária do PNSC é contraditório, evidenciando tanto os dados pretéritos, relativos às disputas territoriais, resultado da contradição fundiária, quanto os novos dados sobre a evolução temporal das doações recebidas pelo ICMBio, mostrando um cenário por vezes frágil com relação ao respaldo jurídico envolvendo as interpretações do Decreto $\mathrm{n}^{\circ} 70.355 / 1972$.

E, diante do segundo momento deste estudo, é possível entender que os camponeses no entorno (área não regularizada), mantêm níveis significativos e importantes de conservação e seguem articulando e pressionando para que as demandas judiciais reconheçam a caducidade do Decreto de 1972, bem como os demais agravos posteriores, para que continuem no território Canastreiro.

Por fim, ressalta-se a importância das Geotecnologias para a construção analítica deste estudo, sobretudo, através do Geoprocessamento e Sensoriamento Remoto que permitiram o mapeamento e leitura dos dados sobre cobertura e uso da terra no PNSC, revelando o papel do campesinato no processo de etnoconservação no Brasil, como resistência e possibilidades para uma alternativa territorial da conservação no país.

\section{Referências}

BARBOSA, C. Territórios de vida dos pequenos produtores de queijo da Serra da Canastra: um estudo sobre a relação entre produção camponesa e espaços naturais protegidos nas nascentes do rio São Francisco, Minas Gerais. Dissertação (Mestrado em Geografia). Uberlândia, MG, UFU, 2007.

BRASIL. Casa Civil. Relatório do GTI instituído pelo Decreto de 24 de janeiro de 2006, relativo ao PNSC. Brasília, 2006. 
BRUNDE, A.; MENDONÇA, M. R. Os impactos do agronegócio dos agrocombustíveis sobre as famílias camponesas - Município de Ipiranga de Goiás/Brasil. Anais do IV SINGA, 2009.

DIEGUES, A. C. S. O mito moderno da natureza intocada. São Paulo: HUCITEC, 1998.

DIEGUES, A. C. S. Etnoconservação da natureza: enfoques alternativos. DIEGUES, Antonio C. (Org.). Etnoconservação: novos rumos para proteção da natureza nos trópicos. São Paulo: HUCITEC, NUPAUBUSP, ANNABULME, 2000.

ESPÍRITO-SANTO, M. M. et al. Understanding patterns of land-cover change in the Brazilian Cerrado from 2000 to 2015. Philosophical Transactions of the Royal Society B: Biological Sciences, v. 371, p. 20150435, 2016.

FAO. Planning for sustainable use of land resources. FAO land and water bulletin 2. Rome: FAO, 1995.

FERNANDES, V. S. R. Entre a regulação e a emancipação social: desafios à continuidade do lugar frente ao Parque Nacional da Serra da Canastra - MG. Dissertação (Mestrado em Sociologia). Belo Horizonte: UFMG, 2012.

FERREIRA, G. H. C. Território e recursos naturais: um estudo sobre a resistência camponesa no entorno do Parque Nacional da Serra da Canastra - MG. Anais do V SINGA. Belém: Ed. Açaí, 2011.

FERREIRA, G. H. C. A Regularização Fundiária no Parque Nacional da Serra da Canastra e a Expropriação Camponesa: da Baioneta à Ponta da Caneta. 2013. Dissertação (Mestrado em Geografia). FFLCH, Universidade de São Paulo, São Paulo, 2013.

FERREIRA, G. H. C. O Parque Nacional da Serra da Canastra - MG: algumas propostas, conflitos e incertezas territoriais. Revista Cerrados, v. 13, p. 111-139, 2015.

GOULART, A. A.; RISSO, L. C. Estudo da viabilidade de alternativas econômicas compatíveis com a conservação na Zona de Amortecimento do Parque Nacional da Serra da Canastra limitada no município de São Roque de Minas/MG. Anais do Encontro Nacional de Geógrafos. Porto Alegre: AGB, 2010.

IBGE. Manual técnico de uso da terra. Manuais técnicos em geociências. Rio de Janeiro: IBGE, 2006.

ICMBio. Conquistas na regularização fundiária, 31 de agosto de 2017. Disponível em: <http://www.icmbio.gov.br/portal//ltimas-noticias/20-geral/9122-conquistas-na-regularizacao-fundiaria > Acesso em: 10 jan. 2018.

LIMA, J. R. Compensação agiliza regularização fundiária em parques. Brasília 17/05/2011. Disponível em: $\quad$ http://www.icmbio.gov.br/portal/ultimas-noticias/20-geral/881-compensacao-agiliza-regularizacaofundiaria-em-parques >. Acesso em: 02 fev. 2018.

LEITE, M. R. Sensoriamento Remoto aplicado à Análise temporal da relação uso da Terra/Temperatura e Albedo de superfície na Bacia hidrográfica do Rio Vieira no Norte Minas Gerais. Dissertação (Mestrado em Geografia). Uberlândia, MG, UFU, 2011.

LUZ, M. Carijos e barbaquás no Rio Grande do Sul: resistência camponesa e conservação ambiental no âmbito da fabricação artesanal de erva-mate. Dissertação (Mestrado em Geografia). UFRGS/Faculdade de Ciências Econômicas. Porto Alegre, 2011.

OLIVEIRA, L. C. A. Produtores rurais e Parque Nacional: um estudo de caso na Serra da Canastra - MG. Dissertação (Mestrado em Administração Rural). Escola Superior de Agricultura de Lavras, Lavras, 1992.

SANTOS, A. A. Paisagem do Parque Nacional da Serra da Canastra e de sua zona de amortecimento MG: análise de padrões espaciais a partir de árvore de decisão e métricas de paisagem. Dissertação (Mestrado em Análise e Modelagem de Sistemas Ambientais). Belo Horizonte: UFMG, 2014.

SANTOS, A. A.; MACHADO, M. M. M. Paisagem do Parque Nacional da Serra da Canastra e de sua zona de amortecimento. MG. RA'EGA: o Espaço Geográfico em Análise, v. 33, p. 75-93, 2015.

SIMONCINI, J. B. V. B. Produzir para viver ou viver para produzir: conflitos vividos pelos produtores familiares e as estratégias de resistência no território do queijo Canastra. Tese (Doutorado em Geografia). Santa Maria: UFSM, 2017.

VON AHN, M. M; SANTOS, F. C. A.; SIMON, A. L. H. Identificação e análise da cobertura e uso da terra voltada à conservação do patrimônio geomorfológico das Guaritas do Camaquã - RS. Revista Geonorte, v. 10, p. 327-334, 2014. 